\title{
Restructuring of the Banking Sector Through Merger: Case of Tunisian Banks
}

\author{
Manel Bekri \\ Dept of Economics, Faculty of Economics and Management of Sfax Tunisia \\ Po Box43, Moulares Gafsa 2161, Tunisia \\ E-mail: Manelbekri2020@gmail.com
}

Received: Nov. 10, $2021 \quad$ Accepted: Dec. 14, $2021 \quad$ Published: Dec.s 21, 2021

doi:10.5296/ifb.v8i2.17931ＵRL: http://dx.doi.org/10.5296/ifb.v8i2.17931

\begin{abstract}
In the classical economy, the business is always looking for growth. It tries to protect itself against disappearance and to enter new markets to ensure its growth. It resorts to the merger or the takeover of local companies to more easily solve certain problems. Development today by $M \& A$ is the most popular mode. In the context of merger acquisition processes, and its relationship with organizational, process, strategic, economic, political and cultural factors, our paper is designed to study the impact of these various factors on the merger-acquisition.

To understand these relationships, we used principal component analysis, ANOVA analysis and multiple regression. A questionnaire was designed on the basis of a documentary analysis leading to the collection of 80 observations, collected from functionaries in the Tunisian banking sector during the period 16 December to 6 January 2016. The results show that the various factors have a positive impact on the success of the merger acquisition operation. It should be noted that the organizational factor is the most influential factor on the acquisition merger process and the least influential economic factor.
\end{abstract}

Keywords: merger acquisition, bank, determinants of success, Tunisia 


\section{Introduction}

In the traditional economy, the company is always looking for growth. It is called to increase the means of production, to create values, ... It is trying to protect itself from extinction and to penetrate new markets to ensure its growth. It is therefore exposed to two types of growth, namely internal growth using its own resources and following a strategy of self-growth. Develop, or to an external growth by turning to external means for the increase of the means of production by following a policy of fusion-acquisition.

The recourse to the merger or the takeover of local companies now allows them to more easily solve certain problems such as the acquisition of new markets, the constitution of a distribution network, the training of personnel, the improvement of their profit margins, their technological and / or organizational knowledge. Development today by M\&A is the most popular mode. This phenomenon does not represent a strategy in itself but a tool serving the objectives of the company. In practice, since the beginning of 2015, the M\&A market has shown a return to strength in a good number of sectors: not a day goes by without the press reporting new M\&A transactions. Today, there is no suspense: the fever of mergers and acquisitions reigns well over the major global companies: oil, hi-tech, pharmacy, insurance, especially banks (Note 1), but taking different legal and financial forms.

Today, globalization and technological and financial innovations are causing profound changes in the banking sphere. Technological innovations have helped to simplify technical and geographical barriers and, consequently, to unify banking markets. With this in mind, our choice of study was based on the banking sector. Within our research, we analyze the fact that many factors influence the success of a bank M\&A transaction. Our study could have been applied to many of the sectors involved in these reconciliation operations, given that businesses, regardless of their sector of activity, often have a similar organizational structure and thus face the same difficulties in achieving performance. Developing and emerging countries are increasingly contributing to foreign investment around the world through mergers and acquisitions (Nayyar, 2008).

Companies in some countries have even become major players in the global market for this operation. Examples include India (Nayyar, 2008) and China (Luedi, 2008). Due to a glaring lack of data, there are very few studies on mergers and acquisitions in developing countries. Kamaly (2007) analyzed M\&A transactions targeting a business in a developing country.

The study of mergers and acquisitions in the Maghreb countries is practically non-existent for various reasons. The most important is the absence, until a relatively recent period, of a real market dynamic that drives the economies of these countries. Family ownership of companies and the lack of efficient financial markets largely explain this lack of dynamism.

At the macro-economic level, Tunisia has made several new international commitments to overcome the effects of the international economic crisis that are dictated by new imperatives to Tunisian businesses.

Tunisia experienced the first merger acquisitions from the 1980s onwards. To our knowledge, only the study by Ati and Srairi (2004) dealt with this phenomenon in Tunisia. 
This article aims to present a multidimensional view of acquisition mergers in the Tunisian banking sector. Our work therefore aims to provide a complementary light, situated halfway between strategic management and organizational behavior. He thus tries to answer one of the most stimulating questions of the disciplines: What are the determinants that explain the success of the bank merger-acquisition in a Tunisian context?

As such, it is significant to note that this research offers a reflection on the phenomenon of bank mergers and acquisitions, with a view to acquiring technologies and creating innovations. This phenomenon seems to be becoming a major concern of the managers of companies belonging to the banking sector.

\section{Literature Review}

The definition of "merger" and "acquisition" is central to starting our research. This phenomenon is very vague for this, it is necessary to ask some questions: What is a merger-acquisition? How does his process work?

According to Aslanoff (2013), we refer to a merger when the combination of two companies (A) and (B) results in a new company (C): the merger is therefore the combination of two independent entities, so the objective is to create a new whole. Fusion may also consist of the absorption of (B) by (A).

On the report to Meier and Schier (2006), mergers and acquisitions are mergers or acquisitions of target companies, carried out through a share purchase or exchange. According to Melchior (2012), M\&A is a mode of growth that enables companies to strengthen their competitive position, access new markets, internationalize, acquire new skills and diversify.

This operation is considered an essential mode of development in the company's strategy, eating and fiancé and a mode of growth that allows companies to strengthen their competitive positions, internationalize and diversify.

For Ceddaha (2010), it is the pooling of assets or economic interests between two or more entities. Most often this pooling between two or more entities. Economically, the merger is defined as the economic operation aimed at integrating into a single undertaking all the means of production available to the company or companies involved (Steven, 2008).

Legally according to DZ entreprise (2014), the merger is defined as a contractual phenomenon by which, for a plurality of companies, only one is replaced, in two possible variants by incorporation of a new company in which two or more pre-existing companies come together.

Overall, all the definitions of the merger are in agreement that the merger operations involve the confusion of assets and the pooling of the assets and liabilities of two companies within the same personality. It should be noted that there are no legal limits. In the majority of cases, mergers involve two companies that decide to join together to form one.

After defining the term "merger", we now move to the definition of acquisition, we are 
talking about acquisition when a company A, known as a "purchaser", buys an interest in a company B, called a "target or acquired company". Thus, Company A can influence B's decision-making knowing that it is not obliged to own B's capital.

Based on the thinking of Johnson et al. (2011), the acquisition corresponds to the acquisition of an organization by another organization.

In the same vein, Bunel et al. (2008) point out that merger and acquisition transactions can be defined as an external growth transaction that involves the partial or total acquisition of control of a so-called "transferor" to the "beneficiary" company. But legally, these two operations are different. To overcome this confusion, we dedicate this part to these two principles, the presentation of their types as well as to the main differences that distinguish them.

Meier and Schier, in 2009, proposed two types of merger. The first type is a merger by absorption which is an operation in which the acquired company disappears while its assets are transferred in their entirety to the acquiring company. It involves the simultaneous execution of several operations such as the increase of the capital of the absorber, the exchange of securities between the shares of the acquired and acquiring companies, the universal transfer of the assets of the absorbed to the absorber, the dissolution of the absorbed. The second type is the merger by creation of a new company is a transaction in which the two original companies disappear in favour of a third newly created company. The fusion mechanisms are relatively similar to those of fusion absorption. It involves the simultaneous execution of several operations such as the creation of a new company, the exchange of shares of the disposing companies for shares of the new company, an increase of capital carried out by the newly created company, the dissolution of the transferring companies. Like, they proposed two types of acquisition.

The first type is the acquisition by purchase of OPA (Note 2) shares which consists in transferring ownership of the controlling interests of the shareholders of a target company to the acquiring company. The transfer takes place within a simple framework of the actions or shares concerned.

The second type is the share exchange acquisition where the initiating company offers the shareholders of the target company to exchange their shares for the shares of the initiating company. In practice, OPE (Note 3) can be a prerequisite for a real merger.

An earlier study in 2000 by Mucchielli and Kohler established a typology of mergers and acquisitions by distinguishing between horizontal mergers and acquisitions, vertical mergers and acquisitions and conglomerate and centric mergers and acquisitions.

$\checkmark$ The horizontal acquisition merger: when two competing companies combine into one company. For Mucchielli and Kohler (2000), "In a horizontal merger, two competing companies come together to form one." Hartmann and Geismar (2003) argue that "horizontal mergers and acquisitions involve companies belonging to the same industry and directly competing with each other." 
$\checkmark$ The vertical acquisition merger: the two companies get together, have customer/supplier relations, that is to say, allows to remove the intermediaries, to obtain advantages of the costs on the competitors, to increase the market power of the firm. According to Mucchielli and Kohler (2009), a vertical merger results in the integration of two companies that could only maintain contractual relations between customers and suppliers.

$\checkmark$ Merger conglomerate acquisition: It is the grouping of two companies that provide different goods. They are also called unrelated acquisition merger or oblique acquisition merger. Mr. Habeck and Tram (2001) argue that conglomerate mergers bring together companies with no links to each other, they do not correspond to a sectoral strategy, but to a diversification strategy at group level. The goal is to achieve a financial balance because we dilute the risk. Thus, Hartman and Geismar (2003) have determined that conglomerate mergers and acquisitions involve for companies with completely different trades. In the light of these ideas Steven and Bragg (2008) have shown that these types of acquisition mergers concern the rapprochement of firms whose businesses are unrelated to each other.

$\checkmark$ Merger centric acquisition: according to Hartmann and Geismar (2003) are called mergers and acquisitions related diversification. They concern the approximation of activities not belonging to the same market but exercising similar powers. Companies are not directly competitive, but they are expected to exploit synergies that are essentially technological or commercial in nature.

We have summarized the different types of Scan Merge in the table above:

Table 1. M\&A Classification (Aslanoff, 2003)

\begin{tabular}{llll}
\hline $\begin{array}{l}\text { Acquisition Merge } \\
\text { Classification }\end{array}$ & Specificities & Objectives \\
\hline Horizontal & Union between two competing & & \\
& undertakings & - & Increase profits by reducing production costs \\
Vertical & Union between two undertakings belonging & - & Increase productive efficiency \\
& to the same production process & - & Access to new markets \\
& & - & Increase bargaining power vis-à-vis other \\
& & Suppliers & \\
Conglomeric & & - & Achieve overall financial balance \\
& & - & Willingness to diversify by integrating new \\
Union between two companies with & - & Achieve economies of scale \\
& complementary occupations but not & - & Increase market share \\
& belonging to the same sector & - & Diversify \\
\hline
\end{tabular}




\section{Analysis Model and Assumptions}

Mergers and acquisitions in the banking sector have become familiar in most countries around the world. Many of the international and domestic banks around the world are engaged in merger acquisition activities. Let us recall that one of the main objectives of the latter in the banking sector is to reap the benefits of economies of scale.

Through acquisition mergers, banks can achieve significant growth in their operations and reduce their spending to a considerable extent. Another important advantage behind this kind of rapprochement is to strengthen the customer base. Thus, mergers and acquisitions in the banking sector have the capacity to ensure efficiency, profitability, and synergy; these operations also help to train and grow shareholder value.

Numerous studies are concerned with the phenomenon of merger acquisition such as the studies of Mucchielli and Kohler (2009), Meier and Schier (2009) and Schweiger (2002) which assert that for a balance of two entities, mergers and acquisitions are the most oriented mode. Thus, the objective of the acquisition merger operations is not limited only to financial objectives but meets a real need for exchange and collaboration allowing the adaptation of new technological skills and leading to the outcrossing of the few groups.

The bank uses acquisition merger operations to internationalize.

The bank, like any other firm, is interested in creating values and minimizing risks as much as possible and strengthening its competitive position by using a merger that has an impact on governance and then on overall performance.

However, this phenomenon is crucial in the development it is for this reason it is essential to analyze this dominant in a deeper way that is introduced by a case study in our study.

In light of the above, the objective of our work is to answer our research questions:

- So, what are the success factors and the brakes of bank acquisition merger?

- What is the importance of merger acquisition in the banking sector?

- The organizational dimension can be presented by several criteria which are mainly effective communication, personal adhesion, speed of integration?

Effective communication is explained by the rapprochement of cultural presentations to the extent that it conditions the assimilation and interiorization of representative patterns anchored in individual minds. In other words, the communication of a merger takes place in three different moments: preparation, announcement and launch and integration. In this context, Gosselin and Archambault (2001) points out that "the development of integration plans, the achievement of issues, the confrontation of risks, constraints, and the dissemination of shared experiences must be communicated regularly and aligned with the expectations of the various stakeholders".

Similarly, for good communication, there must be a rapid dissemination of information both internally and externally. On the same day, prior to notification of the merger by the media, 
the CEO of the firm had to officially release the news to his employees.

Personal adhesion occurs when the personnel of two firms acquire a new nationality of the other firm. In other words, staff buy-in is because staff are able to accept strategic decisions and know how to work with a team. Similarly, competency management is at the heart of the successful acquisition merger process. To achieve a successful acquisition merger transaction, we need to develop an adequate skills management policy. Thus, the human resources remain at the bottom of the immense discussions of failures of these operations. The importance of these human resources is manifested in the capacity to preserve, mobilize, develop knowledge during a merger acquisition.

According to Aboiron and Frichet (2008), the knowledge of these workers is a tradable asset because they are considered inseparable and indivisible from the workers. This knowledge exists in a specific set of organizational routines.

Speed of integration is an essential phase where members of two entities begin to work together and pool their resources. In this context, the difficulties encountered relate to the environment that will motivate this meeting. It is now established that an important part of the failures is due to difficulties in integrating methods, management processes and information systems. Thus, the integration phase, once the acquisition or merger is formalized, is the real key to the success of the operation (Note 4). It must therefore be kept in mind that this process of integration remains difficult, uncertain and fraught with risks. According to Shrivastava (1986), the merger process has three levels of integration; procedural integration (information and management system), physical integration (premises) and socio-cultural integration (values) which presents to the author a result of the development of a culture of joint enterprise.

Really, the speed of integration is the main factor in managing the cultural gap. Thus, if this speed is low, the cultural gap formed by the negative consequences on the fusion stability. A demotivation of two staff teams was generated by the negative effects of a low speed of integration. Gosselin (1987) state that "speed is the best ally of successful integration." In other words, the human resources of two firms can work effectively together provided the integration is rapid.

Integration is an essential element in the creation of value in M\&A transactions. Each step of the Scan Merge process presents issues that may affect the performance of the Scan Merge. To manage these problems is to increase their chance of success. Hapeslagh and Jemison (1991) define integration as "a gradual process in which individuals from two organizations learn to work together and cooperate to transfer their strategic resources." Risberg et al. (2003) states that "if we want to understand what happens during the integration process, we must understand how individuals experience this process." The literature in this perspective has highlighted the value of taking into account the psychosociological dynamics in the analysis of organizational change that constitute mergers (Marks, 1982; Marks \& Mirvis, 1983).

In this context, we pose our first hypothesis H1: The Organizational dimension is a factor determining the success of the bank merger. 
Among the success factors, there is effective knowledge sharing and participatory management that supports the movement of energies. In this same perspective, several authors such as Marks and Mirvis (1983) and Cartwright and Cooper (1993) focus their analysis primarily on the mode of organizational combination as well as poor management of the integration process.

The process dimension is manifested by the following items: the setting of the objective of the merger, the type of operations, the integration time management and the type of integration.

Work on the period of integration has made significant progress, with the emergence of a «process current» (Napier, 1989; Haspeslagh \& Jemison, 1991; Meier \& Schier, 2009). This research stream focuses on the management of the integration process for value creation. Almost all authors who have written on this topic recognize that integration is an essential element in creating value in M\&A transactions. In other words, the success of a merger is the result of a process combining strategic and organizational dimension analysis and the achievement of integration (Haspeslagh \& Jemison, 1991; Jemison \& Sitkin, 1986; Larsson \& Fineltin, 1999).

However, procedural integration makes it possible to ensure a shared knowledge management function that promotes the pooling of declarative and procedural knowledge that has hitherto been essentially individual.

Other criteria such as the objectives of the Napier (1989) merger and the profitability of the operation are also to be taken into account. In this context, we pose our second hypothesis H2: The process dimension is a factor determining the success of the bank merger.

One of the most important factors influencing the success of the reconciliation operation is the cultural factor. In the early 1980s, following the publication of a series of works on culture (Peters \& Waterman, 1982; Schein, 1984, 1985), the literature on mergers took up the concept, particularly to analyse cultural differences (Cartwright \& Cooper, 1993).

This, however, for Hofstede (2001) showed in his research that culture brings together a set of values and symbols, helping to differentiate the company and aiming to ensure the coherence and survival of the group.

We can find different characteristics that are the national, regional and local bank culture, the particular history of the bank, the values carried by some charismatic leaders and the professional culture of the employees.

In a merger operation, companies very often concentrate their efforts on the technical and financial aspects and end up neglecting or even ignoring the human and therefore cultural dimensions. It is in this sense that K. E. Samuel (2002) found that "Personnel studies, where they exist, are limited to the numerical issues of payroll and pensions, and do not provide any qualitative analysis of the company's skills or knowledge gaps."

We also cite the culture shock that occurs when two organizations come together, which always translates into a change, that of "culture shock". Even between seemingly close 
enterprises, very large differences can be observed. This is often enough to make the reconciliation fail to lead to the departure of the most competent employees.

Thus, acquisition mergers, whether friendly or unfriendly, can cause «cultural shocks». The cultural change brought about by the merger process then becomes a source of destabilization. Also, Hafsi and Toulouse (1994) did not assert that "cultural change, on the other hand, can lead to aggressive behavior, with people opposed to the very idea of change." According to A Gosselin (1984), these aggressive behaviors can result in negative reactions, tense relationships and sometimes open hostilities. This is something that leaders need to deal with.

In order to limit the risk of failure, it is necessary to identify the main difficulties present in the operation and then to provide solutions.

In this context, we pose our third hypothesis H3: The cultural dimension is a determining factor in the success of bank mergers.

Generally speaking, according to the literature review, the most used indicators, we find turnover, the economic rate of return, the evolution of sales or market shares. Thus, economic theorists such as Fama and French (1992) have long debated that the goal of successful merger should be the maximization of the firm's value by increasing their market share, increasing their profits, their turnover and cost minimization. In this context, globalization is at the heart of the strategy of companies seeking to win positions on the markets. Around the 1970s, growth in the global economy slowed down, resulting in market saturation and increased competition. Therefore, firms begin to sell their non-strategic business and centralize themselves on their core business.

At this stage, the merger or acquisition transaction may be motivated by the acquisition of intellectual property such as patents, trademarks, manufacturing process, databases and research and development centers.

In this context, we pose our fourth hypothesis H4: The economic dimension is a determining factor in the success of bank mergers.

In this context, the authors have therefore sought to understand the strategic reasons for the success of a merger. It was in the 1980s, under the impetus of the article by Lubtakin (1983) on the importance of strategic adjustment, that the researchers taking part in this perspective of strategic management explained the conditions of merger success. According to Habeck et al. (2001) M\&A transactions and transactions are justified by the creation of value. They note that "When companies merge, the focus is on the good news of greater efficiency, increased potential and benefits, value creation and synergy." Thus, the creation of value corresponds to the creation of synergy. Synergy exists when the value of the two entities combined is greater than the sum of their individual values. Due to its importance, synergy was chosen as a variable for measuring fusion success by Larsson and Finkelstein (1999). Kusstatscher and Cooper (2005) argue that the firm seeks to increase its power of domination and influence. They underline that it is a question for the buyer to use mergers and acquisitions as means to increase its power of domination or influence in the market. 
This strategy is strongly linked to the firm's ability to act in a discretionary manner on the competitive game by deciding, for example, to reduce the quantities produced in order to be able to increase its prices or impose on competitors." The dominance strategy manifests itself in the development of the monopoly position if the firm has complete market surveillance and requires its business practices. In this context, any firm in the event of competition has a fundamental need to innovate. Innovation is an essential requirement for the latter and for all companies in a competitive situation. The increase in reconciliation operations shows a new trend which concerns the willingness of firms to act in order to innovate. In this context, technological development generates the birth of technological and telecommunications tools. For this, some firms are looking for fusion in order to obtain a new technology and give more integrated and developed products.

To innovate, hinder the actions of its competitors and strengthen its power, the firm always seeks to capture specific resources through the transfer of specific skills, the transfer of technology and the acquisition of famous brands. Therefore, the merger or acquisition operation makes the target company a source of resources that enhances and develops the skills and faculties of the acquiring firm (Note 5).

In this context, we pose our fifth hypothesis H5: The Strategic dimension is a factor determining the success of the bank merger.

Another factor determining the success of a bank acquisition merger is transparency and fairness in the appointment of managers. Technological development leads to diversification into communication tools for disseminating information, such as Internet and e-mail messages, letters to staff and interviews with staff (Note 6). For the communication system to succeed, the presence of total transparency is essential. As a result, this communication must contain the right and the wrong information. Exactly the communication is about the appointment of different positions, the selection criteria. At the same time, bank officials must be trained in the new computer system and procedures. During the implementation of this system, each official received useful and clear information. This information must also be written and kept in order to be used as a reference at the appropriate time.

According to Demeure (2000), the multiplicity of changes and challenges makes the management and management of the merger or acquisition period a key factor in the success of the merger transaction.

In this context, we pose our sixth hypothesis H6: The political dimension is a determining factor in the success of bank mergers.

Specifically, our conjecture leads us to the following hypotheses:

$\mathrm{H} 1$ : The Organizational dimension is a determining factor in the success of a bank merger?

$\mathrm{H} 2$ : the process dimension positively influences the bank merger?

H3: Is culture a factor in the success of the bank merger?

H4: The economic dimension is a key factor for the success of a bank merger? 


\section{Macrothink}

H5: Strategic management positively influences the success of a bank merger?

H6: the political dimension positively influences the success of the bank merger?

To better explain our model, it is translated by the following figure

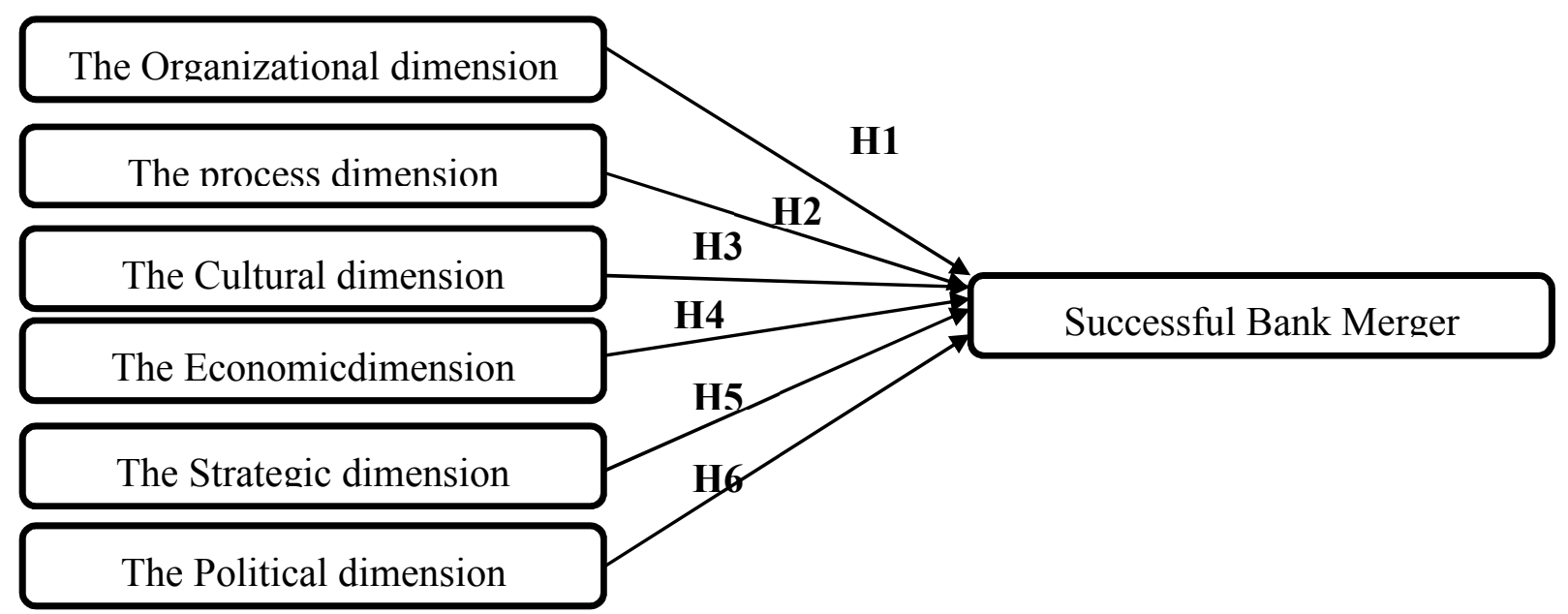

Figure 1. Research model (author)

\section{Research Methodology}

"Analysis is the gathering and processing of information in a form that can provide answers to the questions asked" (Zghal, 1992).

In theory, for each variable we grant a hypothesis and then we make a summary diagram of the hypotheses to know how to draw the model. This research follows a hypothetical-deductive methodology. It tries to confirm or refute the assumptions made. At this stage of research, and after having operationalized the endogenous and exogenous variables, the researcher is faced with more than a choice for the implementation of these variables and their treatments.

We find a problem with the choice of data analysis methods. The choice of method undoubtedly reflects the quality of the data collected. It thus makes it possible to reveal or not a satisfactory validation of the results of the chosen model.

Like any study, we began our analysis with a descriptive analysis where we described our sample. Then we opted for a Core Component Analysis (PCA) to reduce the information contained within our variables (questionnaire items, for example, for a quantitative survey). Finally, we performed a linear regression analysis to identify the link between the dependent variable and the independent variable.

\section{Data}

The survey data were collected and was administered by direct contact (face-to-face) to 
branch heads, senior managers, and Tunisian bank staff. Data collection was conducted during the period of December 16 to January 6, 2016. The questionnaire was developed to measure the success factors of the merger acquisition transaction in the banking sector. The impact of the various factors on the latter is based on a five-point scale (1: strongly disagree and 5: strongly agree). The number of items in our questionnaire is 22 items.

The survey data were collected and was administered by direct contact (face-to-face) to branch heads, senior managers, and Tunisian bank staff. Data collection was conducted during the period of December 16 to January 6, 2016. The questionnaire was developed to measure the success factors of the merger acquisition transaction in the banking sector. The impact of the various factors on the latter is based on a five-point scale (1: strongly disagree and 5: strongly agree). The number of items in our questionnaire is 22 items.

\section{Measures}

We wanted to explore in detail the relationship between different factors and the success of the bank merger operation. Thus, a model was adopted to answer our questions and verify our hypotheses which is presented in Figure 1. We seek the impact of the organizational dimension, the process dimension, the cultural dimension, the economic dimension, the strategic dimension and the political dimension on the success of the bank merger.

Our model consists of seven components. Six components represent the factors influencing the success of the bank merger and one component represents the bank merger (Appendix A):

$\checkmark$ Organizational: measured by effective communication, personal buy-in, speed of integration $(\mathrm{Q} 1, \mathrm{Q} 2, \mathrm{Q} 3)$. The respondent has three questions that address these factors.

$\checkmark$ The process dimension: measured by setting the objective of the merger, the type of operations, the integration time management and the type of integration (Q4, Q5, Q6). The respondent has three questions that address these factors.

$\checkmark$ The cultural dimension measured by the culture management of the bank, culture shock (Q7, Q8). The respondent has two questions that address these factors.

$\checkmark$ The economic dimension is measured by profitability, profit maximization and increased market share (Q9, Q10, Q11). The respondent has three questions that address these factors.

$\checkmark$ The strategic dimension: measured by the creation of value (synergy), the search for innovation, and the search to increase the power of domination (Q12, Q13, Q14). The respondent has three questions that address these factors.

$\checkmark$ The political dimension: measured by timeliness in appointment and transparency and fairness in appointment of manager (Q15, Q16). The respondent has two questions that address these factors.

$\checkmark$ The Performance: measured by positive financial outcome (Q17). Respondent has a question that addresses this factor. 
Our factors are presented in the following model:

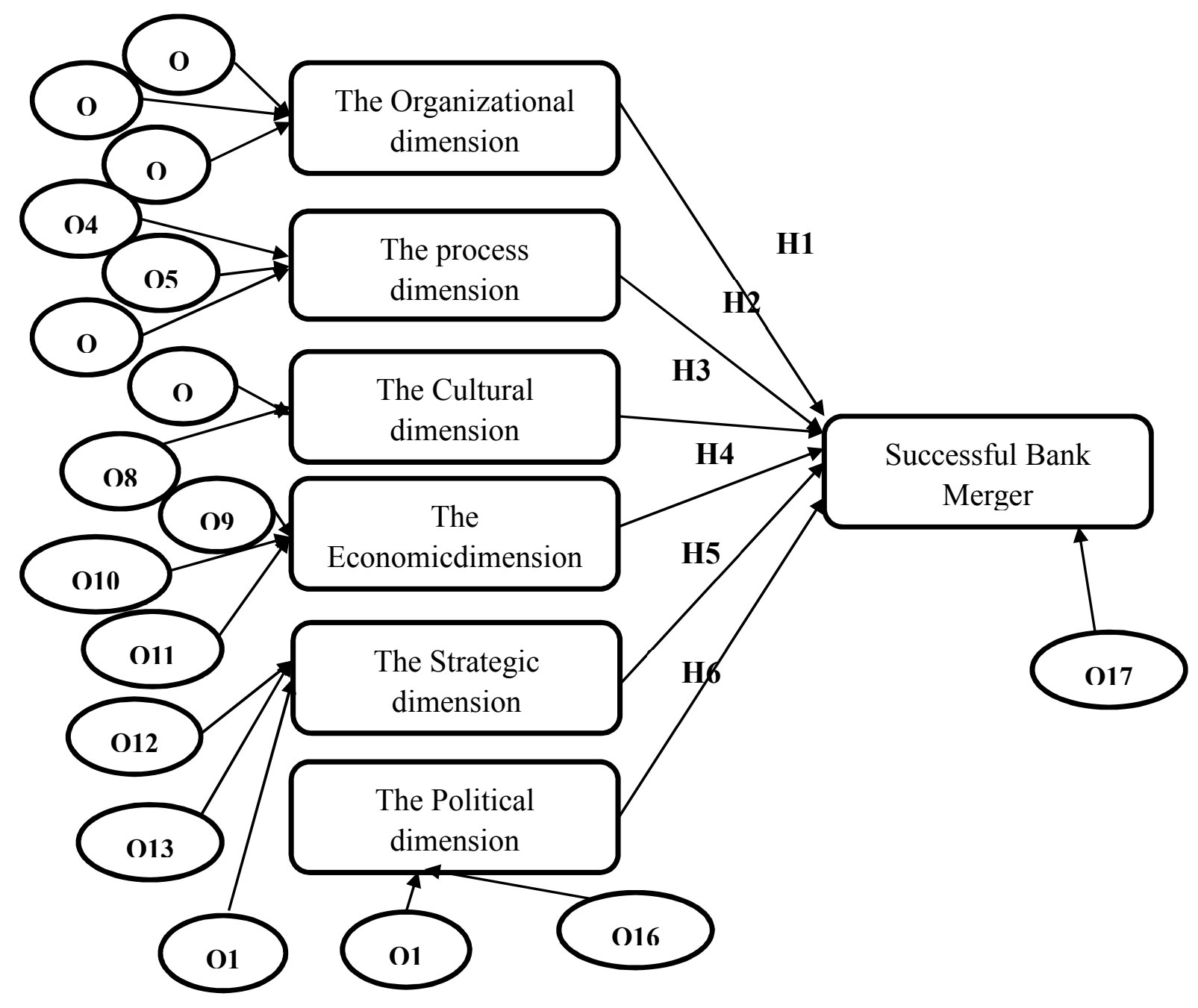

Figure 2. Study model

\section{Data Analysis and Discussions}

We begin our analysis by calculating the relative importance index for each variable in the questionnaire according to the formula of (Digalwar \& Sangwan, 2011; Digalwar et al., 2013). This index expresses the importance of each variable in the questionnaire. All our variables are important and preferred. As a result, we do not need to eliminate any questionnaire variables. Then we measured questionnaire reliability. To do this, we used the Cronbach alpha coefficient which must be higher than 0.7 for a good internal consistency of the different scales used. In, our research for all questions, we used a measure that follows the Likert scale by five points, for which our index is high and fulfilled the Hair condition (Hair et al., 2017). 
Table 2. Reliability statistics

Cronbach's alpha

Cronbach's alpha based on normalized

Number of elements elements

We apply factor analysis on our variables to render factors that carry the maximum amount of information. To apply this analysis, several conditions must be met. We have to observe the correlations of the variables, the KMO index (Kaiser-Mayer-Olkin) and the Bartlett sphericity test (Norusis, 1994; Digalwar \& Sangwan, 2011).

If at least two of these conditions are verified, it is possible to continue the analysis.

According to the correlation matrix, several variables are strongly and moderately correlated, so factorization is possible. In our case, the KMO index is 0.798 , it is considered average and acceptable (Pallant, 2016). Finally, the Bartlett sphericity test is very significant because it is equal to 0.000 , well below 0.05 . In conclusion, we can interpret the result of the factor analysis.

In our research, we have chosen only the components with eigenvalues greater than 1 , the number of components we must choose is based on the maximum return of information.

The results of the factor analysis of different dimensions are summarized below:

$\checkmark$ For the organizational dimension, we selected a single component that explained $91.919 \%$ of the variance or all of the information. This component represents an effective communication measure (Q1).

Table 3. Factorial analysis of the organizational dimension variable

Total variance explained

\begin{tabular}{lllllll}
\hline components & \multicolumn{2}{l}{ initial eigenvalues } & & \multicolumn{2}{l}{$\begin{array}{l}\text { extractions sum of squares of the factors } \\
\text { retained }\end{array}$} \\
\cline { 2 - 6 } & Total & \% variance & \% cumulative & Total & \% variance & \% cumulative \\
\hline 1 & 1.838 & 91.919 & 91.919 & 1.838 & 91.919 & 91.919 \\
2 & .162 & 8.081 & 100.000 & & & \\
\hline
\end{tabular}

For the process dimension, we selected a single component that explained $83.997 \%$ of the variance or all of the information. This component represents a measure of integration time management and type of integration (Q6). 


\section{Macrothink}

Table 4. Factorial analysis of the processual dimension variable

Total variance explained

\begin{tabular}{lllllll}
\hline components & \multicolumn{2}{l}{ initial eigenvalues } & \multicolumn{5}{l}{$\begin{array}{l}\text { extractions sum of squares of the factors } \\
\text { retained }\end{array}$} \\
\cline { 2 - 7 } & Total & \% variance & \% cumulative & Total & \% variance & \% cumulative \\
\hline 1 & 1.680 & 82.997 & 83.997 & 1.680 & 83.997 & 83.997 \\
2 & .320 & 16.003 & 100.000 & & & \\
\hline
\end{tabular}

For the cultural dimension, we selected a single component that explained $74.274 \%$ of the variance or all of the information. This component represents a culture shock measure (Q8).

Table 5. Factorial analysis of the cultural dimension variable

Total variance explained

\begin{tabular}{lllllll}
\hline components & \multicolumn{2}{l}{ initial eigenvalues } & \multicolumn{3}{l}{$\begin{array}{l}\text { extractions sum of squares of the factors } \\
\text { retained }\end{array}$} \\
\cline { 2 - 7 } & Total & \% variance & \% cumulative & Total & \% variance & \% cumulative \\
\hline 1 & 1.680 & 83.997 & 83.997 & 1.680 & 83.997 & 83.997 \\
2 & .320 & 16.003 & 100.000 & & & \\
\hline
\end{tabular}

For the economic dimension, we selected a single component that explained $71.440 \%$ of the variance or all of the information. This component represents a measure of the increase in market share (Q11).

Table 6. Factorial analysis of the economic dimension variable

\begin{tabular}{lllllll}
\hline components & \multicolumn{2}{l}{ initial eigenvalues } & \multicolumn{3}{l}{$\begin{array}{l}\text { extractions sum of squares of the factors } \\
\text { retained }\end{array}$} \\
\cline { 2 - 6 } & Total & \% variance & \% cumulative & Total & \% variance & \% cumulative \\
\hline 1 & 1.429 & 71.440 & 71.440 & 1.429 & 71.440 & 71.440 \\
2 & .571 & 28.560 & 100.000 & & & \\
\hline
\end{tabular}

For the strategic dimension, we selected a single component that explained $75.769 \%$ of the variance or all of the information. This component represents a measure of research to increase the power of domination (Q14). 
Table 7. Factor analysis of the strategic dimension variable

\begin{tabular}{|c|c|c|c|c|c|c|}
\hline \multirow[t]{2}{*}{ components } & \multicolumn{3}{|c|}{ initial eigenvalues } & \multicolumn{3}{|c|}{$\begin{array}{l}\text { extractions sum of squares of the factors } \\
\text { retained }\end{array}$} \\
\hline & Total & $\%$ variance & $\%$ cumulative & Total & $\%$ variance & $\%$ cumulative \\
\hline 1 & 1.515 & 75.769 & 75.769 & 1.515 & 75.769 & 75.769 \\
\hline 2 & .485 & 24.231 & 100.000 & & & \\
\hline
\end{tabular}

For the policy dimension, we selected a single component that explained $81.811 \%$ of the variance or all of the information. This component represents a measure of transparency and fairness in the appointment of a manager (Q16).

Table 8 . Factor analysis of the political dimension variable

\begin{tabular}{lllllll}
\hline components & \multicolumn{2}{l}{ initial eigenvalues } & & \multicolumn{2}{l}{$\begin{array}{c}\text { extractions sum of squares of the factors } \\
\text { retained }\end{array}$} \\
\cline { 2 - 7 } & Total & \% variance & \% cumulative & Total & \% variance & \% cumulative \\
\hline 1 & 1.636 & 81.811 & 81.811 & 1.636 & 81.811 & 81.811 \\
2 & .364 & 18.189 & 100.000 & & & \\
\hline
\end{tabular}

On the basis of the IBMSPSS software, the performance and success of the bank merger, the organizational dimension, the cultural dimension, the process dimension, the political dimension were used as control variables for the exogenous variable, the strategic and economic dimensions.

Using the ANOVA technique, the calculation is done by transforming the two variations 'intergroup and intragroup' into a variance ratio that is obtained by dividing each of them by the appropriate number of degrees of freedom. We thus obtain a coefficient $F$ of FISHER-SNEDECOR whose statistical properties are known.

We compare the calculated value of $F$ with its critical value, a fixed $\alpha$ threshold and the corresponding number of degrees of freedom.

\subsection{The Organizational Dimension}

For the reference sample, the FISHER-SNDECOR table gives a value of 3.96 for $\alpha=0.05$ for 1 to 78 degrees of freedom. The ones we calculated is 184.507 which is well above the target coefficient. We therefore conclude that the data collected make it possible to rule in favor of a highly significant influence $(F=184.507$ and $\mathrm{sig}=0.000)$ of organizational dimension on the success of the bank merger. The stronger the organizational approach is managed the stronger will be the success of the bank merger.

Thus, based on the simple regression test, the $\mathrm{H} 1$ hypothesis is confirmed within the target population. 
Table 9. Model summaries ${ }^{\mathrm{b}}$

\begin{tabular}{|c|c|c|c|c|c|c|c|c|c|c|}
\hline \multirow[t]{2}{*}{ Model } & \multirow[t]{2}{*}{$\mathrm{R}$} & \multirow[t]{2}{*}{$\mathrm{R}^{2}$} & \multirow{2}{*}{$\begin{array}{l}\text { Ajusted } \\
\mathrm{R}^{2}\end{array}$} & \multirow{2}{*}{$\begin{array}{l}\text { standard } \\
\text { error of } \\
\text { estimate }\end{array}$} & \multicolumn{5}{|c|}{ change in statistics } & \multirow[t]{2}{*}{ Durbin-Waston } \\
\hline & & & & & $\begin{array}{l}\mathrm{R}^{2} \\
\text { variation }\end{array}$ & $\begin{array}{l}\mathrm{F} \\
\text { variation }\end{array}$ & $\mathrm{Fd}$ & $\mathrm{Fd} 2$ & $\begin{array}{l}\text { Sig. F } \\
\text { variation }\end{array}$ & \\
\hline 1 & $.838^{\mathrm{a}}$ & .703 & .699 & .639 & .703 & 184.507 & 1 & 78 & .000 & 1.494 \\
\hline
\end{tabular}

Note. a: predicted value: (constant), V.Dimension ORG; b: dependent variable: V.SUCCES.

Table 10. ANOVA ${ }^{\mathrm{a}}$

\begin{tabular}{llllll}
\hline Model & Sum. Sq & Fd & Average. Sq & D & Sig. \\
\hline Regression & 75.338 & 1 & 75.338 & 184.507 & $.000^{\mathrm{b}}$ \\
$1 \quad$ Residue & 31.849 & 78 & .408 & & \\
Total & 107.188 & 79 & & & \\
\hline
\end{tabular}

Note. a: dependent variable: V.SUCES; b: predicted value: (constant), V.Dimension ORG.

\subsection{The Processual Dimension}

The regression test indicates for the reference population an important correlation between the process dimension and the success of the bank merger, the intensity of this relationship is translated by a coefficient (of correlation $\mathrm{R}$ ) whose value is $68 \%$ the adjusted $\mathrm{R}^{2}$ has an accepted score of $0.455 \%$.

To assess the quality of the adjustment of this regression, it uses the FISHER-SNEDECOR test. The question is whether, for the risk $\alpha$ considered, the multiple $\mathrm{R}^{2}$ is significantly different from 0 in the sample studied (Giannelloni \& Vernette, 2001, p. 413). The critical value of $F$, at the $\alpha=0.05$ threshold, for 1 and 78 degrees of freedom, is equal to 3.96. The observed F $(67,070$, sig $=0,000)$ being significantly higher, we can conclude that the quality of the adjustment offered by the regression is significant. There is therefore a significant dependence between the process approach and the success of a bank merger. So, we can confirm our hypothesis H2: The process dimension has a positive impact on the success of bank mergers.

Table 11. Explanatory analysis of simple regression of process dimension variable compared to the success of bank mergers

\begin{tabular}{|c|c|c|c|c|c|c|c|c|c|c|}
\hline \multirow[t]{2}{*}{ Model } & \multirow[t]{2}{*}{$\mathrm{R}$} & \multirow[t]{2}{*}{$\mathrm{R}^{2}$} & \multirow{2}{*}{$\begin{array}{l}\text { Ajusted } \\
\mathrm{R}^{2}\end{array}$} & \multirow{2}{*}{$\begin{array}{l}\text { standard } \\
\text { error of } \\
\text { estimate }\end{array}$} & \multicolumn{5}{|c|}{ change in statistics } & \multirow[t]{2}{*}{ Durbin-Waston } \\
\hline & & & & & $\begin{array}{l}\mathrm{R}^{2} \\
\text { variation }\end{array}$ & $\begin{array}{l}\mathrm{F} \\
\text { variation }\end{array}$ & $\mathrm{Fd}$ & $\mathrm{Fd} 2$ & $\begin{array}{l}\text { Sig. F } \\
\text { variation }\end{array}$ & \\
\hline 1 & .680 & .462 & .455 & .860 & .462 & 67.007 & 1 & 78 & .000 & 1.922 \\
\hline
\end{tabular}




\section{Macrothink}

Table 12. The ANOVA model for the process dimension

\begin{tabular}{llllll}
\hline Model & Sum. Sq & Fd & Average. Sq & D & Sig. \\
\hline Regression & 49.556 & 1 & 49.556 & 67.070 & $.000^{\mathrm{b}}$ \\
$1 \quad$ Residue & 57.632 & 78 & .739 & & \\
Total & 107.188 & 79 & & & \\
\hline
\end{tabular}

\subsection{The Cultural Dimension}

A simple regression between the cultural dimension variable and the fusion success is significant since sig $=0.000$. Don, we can say that the cultural dimension has a positive impact on the success of bank mergers. Our $\mathrm{H} 3$ hypothesis is therefore to be retained.

Table 13. The coefficients of the cultural dimension variable

\begin{tabular}{llllll}
\hline Model & \multicolumn{2}{l}{ non-standardized coefficient } & standardized coefficient & \multirow{2}{*}{ Sig. } \\
\cline { 2 - 4 } & $\mathrm{A}$ & $\begin{array}{l}\text { Standardized } \\
\text { error }\end{array}$ & Beta & \\
\hline (constant) & 2.337 & .298 & & 7.832 & .000 \\
Cultural dimension variable & .425 & .087 & .485 & 4.904 & .000 \\
\hline
\end{tabular}

\subsection{The Economic Dimension}

According to the Schedule..., the model has a value of $\mathrm{R}^{2}=0.184$, i.e., $18.4 \%$ of the economic size dispersion is explained by the success of the bank merger. A percentage that can be accepted in our study.

Table 14. Summary of the economic dimension model

\begin{tabular}{|c|c|c|c|c|c|c|c|c|c|c|}
\hline \multirow[t]{2}{*}{ Model } & \multirow[t]{2}{*}{$\mathrm{R}$} & \multirow[t]{2}{*}{$\mathrm{R}^{2}$} & \multirow{2}{*}{$\begin{array}{l}\text { Ajusted } \\
\mathrm{R}^{2}\end{array}$} & \multirow{2}{*}{$\begin{array}{l}\text { standard } \\
\text { error of } \\
\text { estimate }\end{array}$} & \multicolumn{5}{|c|}{ change in statistics } & \multirow{2}{*}{ Durbin-Waston } \\
\hline & & & & & $\begin{array}{l}\mathrm{R}^{2} \\
\text { variation }\end{array}$ & $\begin{array}{l}\mathrm{F} \\
\text { variation }\end{array}$ & $\mathrm{Fd}$ & $\mathrm{Fd} 2$ & $\begin{array}{l}\text { Sig. F } \\
\text { variation }\end{array}$ & \\
\hline 1 & .429 & .184 & .173 & 1.059 & .184 & 17.572 & 1 & 78 & .000 & 1.396 \\
\hline
\end{tabular}

Table 15. ANOVA of the economic dimension

\begin{tabular}{llllll}
\hline Model & Sum. Sq & Fd & Average. Sq & D & Sig. \\
\hline Regression & 19.708 & 1 & 19.708 & 17.572 & .000 \\
$1 \quad$ Residue & 87.479 & 78 & 1.122 & & \\
Total & 107.188 & 79 & & & \\
\hline
\end{tabular}




\section{Ml Macrothink}

The ANOVA Table 15 shows us that an observed Fisher F value of our model equals 17.572 with sig $=0.000$. So, we accept our hypothesis H4: the economic dimension has a positive impact on the success of the bank merger.

The regression between the success of bank mergers and the economic dimension shows that there is a relationship between the success of bank mergers and the economic dimension.

\subsection{The Strategic Dimension}

A simple regression between the strategic dimension variable and the success of the bank merger is significant since sig $=0.000$. So, we can say that the strategic dimension has a positive impact on the success of the bank merger, H5 is accepted.

Table 16. Strategic dimension ANOVA

\begin{tabular}{llllll}
\hline Model & Sum. Sq & Fd & Average. Sq & D & Sig. \\
\hline Regression & 28.472 & 1 & 28.472 & 28.213 & .000 \\
$1 \quad$ Residue & 78.716 & 78 & 1.009 & & \\
Total & 107.188 & 79 & & & \\
\hline
\end{tabular}

Table 17. The coefficients of the strategic dimension variable

\begin{tabular}{lllllll}
\hline \multirow{2}{*}{ Model } & \multicolumn{2}{c}{ non-standardized coefficient } & standardized coefficient & \multirow{2}{*}{ Sig. } & & \\
\cline { 2 - 4 } & $\mathrm{A}$ & Standardized error & Beta & & \\
\hline (constant) & 1.742 & .383 & & 4.547 & .000 & \\
Cultural dimension variable & .517 & .097 & .515 & 5.312 & .000 \\
\hline
\end{tabular}

\subsection{The Political Dimension}

According to the arguments developed in the H6 hypothesis; the political dimension; the speed in the appointment of the management team and the transparency and fairness in the appointment, positively influence the success of the bank merger. The results of the regression of bank merger success compared to bank merger success, an accepted correlation $6.36 \%$.

The adjusted $\mathrm{R}^{2}$ score is 0.397 . The quality of the adjustment obtained by this linear relationship, estimated at 53.044 for a sig $=0.000$. The critical value of $F=3.96$ at the threshold $\alpha=0.05$ for 1 and 78 degrees of freedom is higher. The political dimension positively influences the success of bank mergers. Consequently, the H6 hypothesis is accepted. 
Table 18. Explanatory analysis of the political dimension variable

\begin{tabular}{|c|c|c|c|c|c|c|c|c|c|c|}
\hline \multirow[t]{2}{*}{ Model } & \multirow[t]{2}{*}{$\mathrm{R}$} & \multirow[t]{2}{*}{$\mathrm{R}^{2}$} & \multirow{2}{*}{$\begin{array}{l}\text { Ajusted } \\
\mathrm{R}^{2}\end{array}$} & \multirow{2}{*}{$\begin{array}{l}\text { standard } \\
\text { error of } \\
\text { estimate }\end{array}$} & \multicolumn{5}{|c|}{ change in statistics } & \multirow[t]{2}{*}{ Durbin-Waston } \\
\hline & & & & & $\begin{array}{l}\mathrm{R}^{2} \\
\text { variation }\end{array}$ & $\begin{array}{l}F \\
\text { variation }\end{array}$ & $\mathrm{Fd}$ & $\mathrm{Fd} 2$ & $\begin{array}{l}\text { Sig. F } \\
\text { variation }\end{array}$ & \\
\hline 1 & .680 & .462 & .455 & .860 & .462 & 67.070 & 1 & 78 & .000 & 1.922 \\
\hline
\end{tabular}

Table 19. Political dimension ANOVA

\begin{tabular}{llllll}
\hline Model & Sum. Sq & Fd & Average. Sq & D & Sig. \\
\hline Regression & 43.388 & 1 & 43.388 & 53.044 & .000 \\
$1 \quad$ Residue & 63.800 & 78 & .818 & & \\
Total & 107.188 & 79 & & & \\
\hline
\end{tabular}

The validated model is represented by the following figure. It shows that the variables belong to the organizational dimension which are summarized in the communication measure variable $(\mathrm{Q} 1)$ better explain the success of the bank merger with a very high correlation coefficient significant $\beta=68.9 \%$ with a sig $=0.000$. In addition, the factor referring to the political dimension (Q16) which is explained by the variable transparency and fairness in the appointment of manager ranks second with a significant impact of which $\beta=19.6 \%$ with sig $=0.036$.

Then the strategic dimension by its variable the search to increase the power of domination (Q14) and the cultural dimension by the variable culture shock (Q8) with a $\beta=7.1 \%$ with sig $=0.0388$ and sig $=0.0398$. For the economic dimension the variable increase in market share (Q11) is characterized by a value of $\beta=6.2 \%$ with $\operatorname{sig}=0.0412$.

Table 20. Multiple regression

\begin{tabular}{llllll}
\hline Model & \multicolumn{2}{l}{ non-standardized coefficient } & $\begin{array}{l}\text { standardized } \\
\text { coefficient }\end{array}$ & t & Sig. \\
\cline { 2 - 4 } & $\mathrm{A}$ & $\begin{array}{l}\text { Standardized } \\
\text { error }\end{array}$ & \multicolumn{2}{l}{ Beta } & \\
\hline (constant) & .320 & .266 & & 1.203 & .023 \\
ORG dimension variable & .644 & .080 & .699 & 8.089 & .000 \\
PROC dimension variable & .105 & .101 & .107 & 1.039 & .030 \\
CUL dimension variable & -.062 & .073 & -.071 & .850 & .039 \\
ECO dimension variable & -.058 & .071 & -.062 & .825 & .041 \\
STRART dimension variable & .071 & .082 & .071 & .869 & .038 \\
POLIT dimension variable & .197 & .092 & .196 & 2.138 & .036 \\
\hline
\end{tabular}




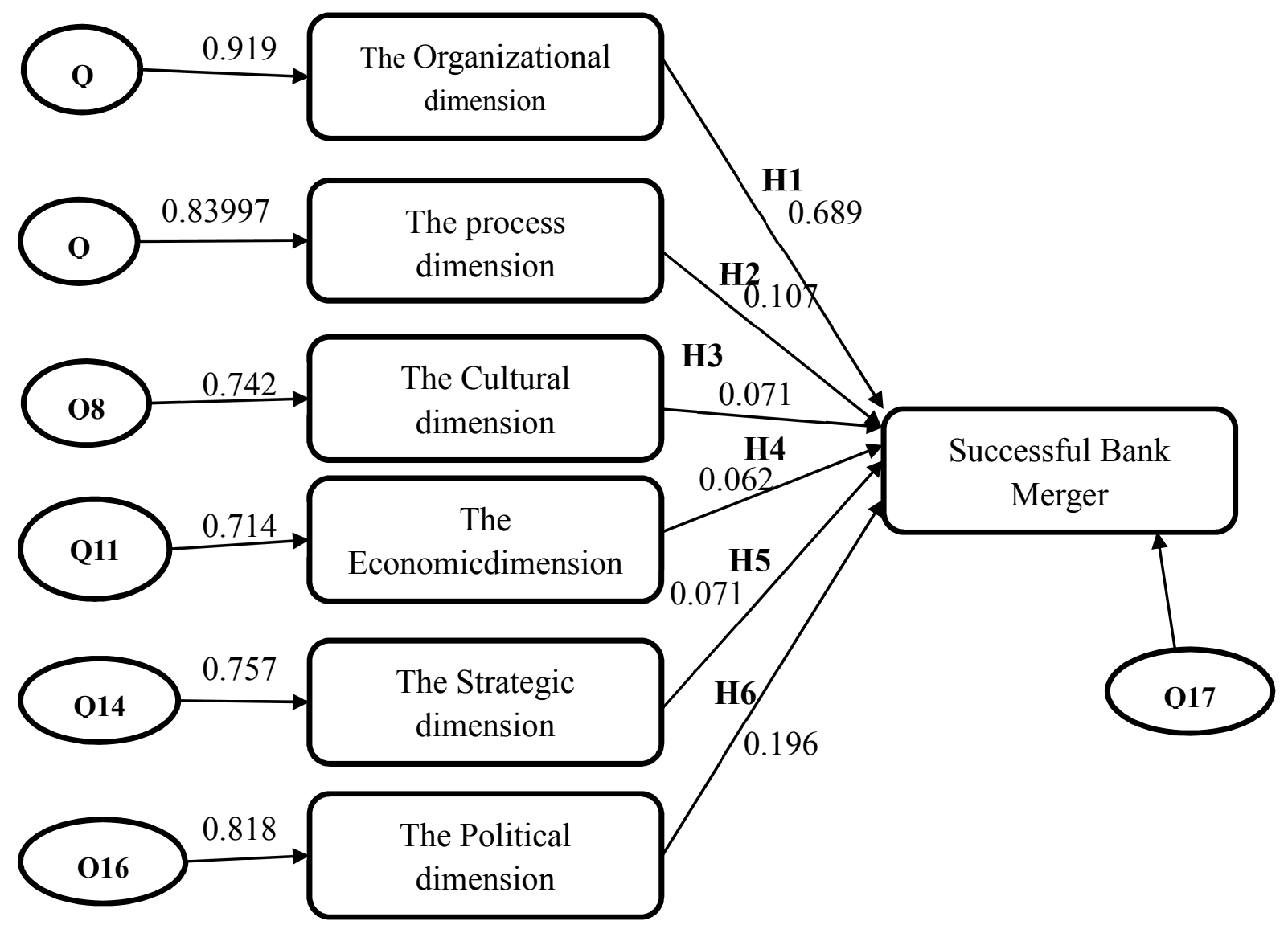

Figure 3. A model and predictive of bank merger success

\section{Conclusion}

Our work has set itself the ambition of studying the determinants of perceived success of bank mergers. The originality of our work lies in the connection we have made with the literature on project management. Thus, our research aims to answer mainly the following question: «What perspective for the success of the bank merger in Tunisia? ».

To do this, we adopted a hypothetico-deductive approach. The survey was carried out in 2015 with 80 bank staff and was based on the technique of a questionnaire-based interview. We have shed light on the determinants of success of a merger. Thus, the objective of this work was to examine the success factors of the bank merger in Tunisia by studying the case of absorption of BH by STB.

In order to analyse the collected data, we opted for the descriptive analysis method to analyze the studied sample and then the ACP method and regressions to study the impact of organizational dimension, cultural dimension, process dimension, economic dimension, strategic dimension, political dimension on the success of bank mergers in Tunisia.

Following these contributions, our work has detected that taking into account the dimensions, allowed a better apprehension of the complexity of the phenomenon of successful bank mergers. Indeed, we concluded that the factors studied helped to influence the success of a 
bank merger operation.

The results of our study justify the coherence and significance of the conceptual model, its internal validity and the choice of its variables. This confirms the idea that the success of the merger could be guaranteed thanks to the variables considered relevant, namely the organizational dimension, the cultural dimension, the process dimension, the economic dimension, the strategic dimension and the political dimension.

Recall that the multiplication of mergers and acquisitions in the banking sector has been fast became inevitable. Banking institutions have had to become "bigger" to survive in the face of globalization, thus generating a multiplication of national or international rapprochement. This increase in mergers and acquisitions is thus one of the most appropriate responses to ongoing changes.

Although the results were sufficient, it cannot be stated that this work has several limitations which are:

The first and main limitation of this work is the small sample size of the study. This leads to access constraints to the field. The second limitation lies in the fact that the only survey method, by questionnaire, gave the few officers the opportunity to unconsciously answer our questions of who caused problems of analysis. The last limit refers to the choice of region; the survey is made in 3 regions which does not give a broader look on the success of bank mergers as a phenomenon newly cited in Tunisia.

Our study suggests two main future avenues of research. The first would be to address the subject of sustainable performance, whether economic, sociological or environmental, in the context of banking mergers and acquisitions.

As part of a second line of research in the future, it would seem interesting to study the gap between the perception of actors of performance and the economic performance of a merger and acquisition operation, particularly in the banking sector.

Always in the extension of our work, questions, offering future topics, can be enlightened:

What are the organizational and human conditions for a successful bank merger?

What are the conditions for integrating a successful "organizational" integration of a bank merger?

At what level of change do individual perceptions and decisions change?

Beyond the perspectives directly related to our topic, what are the factors contributing to a sustainable bank merger performance?

\section{References}

Aboiron, J., \& Edouard, F. (2008). Merger / Acquisition: What management issues?

Aslanoff, A. (2013). Perception of the performance of mergers and acquisitions in the banking sector. Université Nice Sophia Antipoli. 
Ati, A., \& Srairi, S. (2004). Theories and practices of merger operations in Tunisia. Tunisian Economic Review, 63-93.

Bragg, S. M. (2008). Mergers and Acquisitions: A Condensed Practitioner's Guide.

Bunel, D., \& Gonzalez. (2008). Consequence, of mergers and acquisitions on workforce management, an empirical analysis on French data for the wave of the end of années 1990.

Cartwright, C. S., \& Cooper, C. L. (1993). the Role of Culture Compatibility in Successful Organizational Marriage. Academy of Management Executive, 7(2), 57-69. https://doi.org/10.5465/ame.1993.9411302324

Ceddaha, F. (2010). Mergers, acquisitions: valuation, negotiation, engineering.

Demeure, B, (2000). Fusion instructions for use. French Management Review, 131.

Digalwar, A. K., \& Sangwan, K. S. (2007). Development and validation of performance measures for world class manufacturing practices in India. Journal of Advanced Manufacturing Systems, 6(1), 21-38. https://doi.org/10.1142/S0219686707000887

Digalwar, A. K., Tagalpallewar, A. R., \& Sunnapwar, V. K. (2013). Green manufacturing performance measures: an empirical investigation from Indian manufacturing industries. Measuring Business Excellence, 17(4), 59-75. https://doi.org/10.1108/MBE-09-2012-0046

DZentreprise, S. D. (2014). A legal reading: The merger of companies in Algeria.

Fama, E. F., \& French, K. (1992). The Cross-section of expected Stock Returns. Journal of Finance, 47, 427-466. https://doi.org/10.1111/j.1540-6261.1992.tb04398.x

Ferchichi. R., \& Souam, S. (2014). Characteristics and developments of mergers and acquisitions transactions in Tunisia. Les cahiers du cread n¹07-108.

Gosselin, A. (1987). The constraints of integrating a business after a merger or acquisition: how 1 and 1 can work simultaneously. 12(3), 67-74.

Gosselin, A., \& Archambault, J. (2001). The key role of communications in mergers.

Habech, M., Korger, F., \& Tram, M. (2001). After the merger, 7 keys to successful integration. Hafsi, T., \& Toulouse, J. M. (1994). Acquisitions and mergers: strategic choices in conflict with implementation.

Hair, J. F., Black, W. C., Babin, B. J., \& Anderson, R. E. (2017). Multivariate Data Analysis.

Hartmann, L., \& Geismar, R. (2003). es défis de l'intégration.

Haspeslagh, P. C., \& Jemison, D. B. (1991). Managing Acquisitions: Creating Value Through Corporate Renewal. New York: the Free Press.

Hofstede, G. (2001). Culture's conséquences: Comparing values, behaviors, institutions, and organizations across nations. Thousand Oaks, California: sage publications, Inc

Jemison, D. B., \& Sitkin, S. (1986). Acquisitions: The Process Can Be a Problem. Harvard 
Business Review, 64(2), 107-116.

Johnson, G., Whittington, R., \& Scholes, K. (2011). Exploring Strategy.

Kamaly A. (2007). Trends and Determinants of Mergers and Acquisitions in Developing Countries in the 1990's. International Research Journal of Finance and Economics, 8, $16-30$.

Kusstatscher, D. V., \& Cooper, C. L. (2005). Managing Emotions in Mergers and Acquisitions. Edward Elgar Publishing. https://doi.org/10.4337/9781845426774

Larsson, R., \& Finkelstein, S. (1999). Integration Strategic, Organizational, and Human Resource Perspectives on Mergers and Acquisitions: A case Survey of Synergy Realization. Organization Science, 10(1), 1-27. https://doi.org/10.1287/orsc.10.1.1

Lubatkin, M. (1983). Mergers and the performance of the Acquiring Firm. Academy of Management Review, 8(2), 218-226. https://doi.org/10.2307/257748

Luedi, T. (2008). China's track record in M\&A. The McKinsey Quarterly, 3, 77-81.

Marks, M. L. (1982). Merging human resources: A review of current research. Mergers and Acquisition, 17(2), 38-44.

Marks, M. L., \& Mirvis, P. H. (1983). Corporate acquisition: Models of organizational and individual response. Center for Applied Social science, Boston university

Meier, O., \& Schier, G. (2006). Mergers and acquisitions strategy, finance, management.

Melchoir. (2012). le site des sciences économique et sociales. Matthieu Mucherie: les fusions-Acquisitions (F\&A).

Mucchielli, J. L., \& Kohler, P. (2000). déterminants et conséquences des fusions-acquissions. Revue Française de gestion, 131, 19.

Napier, N. K. (1989). Mergers and Acquisitions, Human Resource Issues and Outcomes: A Review and Suggested Typology. Journal of Management Studies, 26(3), 271-289. https://doi.org/10.1111/j.1467-6486.1989.tb00728.x

Nayyar, D. (2008). The Internationalization of Firms from India: Investment, Mergers and Acquisitions. Oxford Development Studies, 36(1), 111-131. https://doi.org/10.1080/13600810701848219

Norusis, M., (1994). Professional Statistics. SPSS, Chicago.

Pallant, J., (2016). SPSS Survival Manual. Mc Graw Hill, Berkshire.

Peters, T., \& Waterman, R. (1982). In Search of Excellence-Lessons from America's Best Run Companies. Warner Books, New York.

Risberg, J. A., Tienari, \& Vaara, E. (1993). Making sense of a transnational merger: Media texts and the (re)construction of power relations. Culture and Organization, 9, 121-137. https://doi.org/10.1080/14759550302806 
Samuel, K. E. (2002). The key role of the human resources function in business mergers. IFSAM conférence gold Coast, Queensland, Australia.

Schein, E. (1985). Organizational Culture and leadership. San Francisco: Jossey-Bass.

Schweiger, D. M. (2002). Merge Right. Business and Economic Review, 48, 3-11.

Shrivastava. P. (1986). Post-merger integration. Journal of Business Strategy, 7(1). https://doi.org/10.1108/eb039143

Thierry, M. (2017). The study of the determinants of mergers and acquisitions transactions for innovative companies: the case of the pharmaceutical industry. Savings and finances. University of Lorraine.

Zghal, R. (1992). Research Methodology in Social Sciences.

\section{Notes}

Note 1. BIT, 1998.

Note 2. OPA: a public offering to buy.

Note 3. OPE: a public offering to exchange.

Note 4. Gérald Brunetto, 2006.

Note 5. his part is inspired by a masterful work "the impact of the merger and acquisition transaction on governance and banking performance".

Note 6. This part is inspired by a masterful work "the impact of the merger and acquisition transaction on governance and banking performance" (p. 19).

\section{Appendix A: Survey}

Survey concerning the Tunisia bank merger.

Thank you for taking a few minutes to answer this questionnaire as part of my research paper entitled «La fusion Bancaire en Tunisie cas: STB et la BH». Thank you for your help and contribution. Ce questionnaire s'inscrit dans le cadre que deux banques se fusionnent.

Check the answer that you feel is most appropriate.

Material Safety Data Sheet:

Sex: Man

\section{Woman}

What is your age group?

20-30 years old 
30-40 years old

40-50 years old

$50-60$ years old

What is your position?

Senior manager

Head of agency

Client-focused or professional

Cashier

1. Organizational dimension

1.1 Do you consider that effective communication (rapprochement in the minds of the individuals of the bank, training on the new IT system, management, effective sharing of knowledge) positively influences the success of the bank merger?

Not agree at all

Rather disagree

Neither agree nor disagree

Somewhat agree

Totally agree

1.2 Do you consider personal buy-in (acceptance of change, acceptance of strategic and organizational decisions, team spirit, need for skills and personal knowledge) to positively influence the success of the bank merger?

Not agree at all

Rather disagree

Neither agree nor disagree

Somewhat agree

Totally agree

1.3 Do you consider the speed of integration (integration of resources, methods, information system, procedural integration (information and management systems) physical integration (premises) socio-cultural integration (values)) positively influences the success of the bank merger?

Not agree at all

Rather disagree 
Neither agree nor disagree

Somewhat agree

Totally agree

2. Process dimension

2.1 Do you consider that setting the merger target positively influences the success of the bank merger?

Not agree at all

Rather disagree

Neither agree nor disagree

Somewhat agree

Totally agree

2.2 Do you consider that the type of transaction (merger by absorption (friendly, hostile), merger by creation of a new company) positively influences the success of the bank merger?

Not agree at all

Rather disagree

Neither agree nor disagree

Somewhat agree

Totally agree

2.3 Do you think that time management and the pace of integration (the importance of speed of integration: time of integration) can present for you a key factor for the success of the bank merger?

Not agree at all

Rather disagree

Neither agree nor disagree

Somewhat agree

Totally agree

3. Cultural dimension

3.1 Do you consider that the culture management of the bank (of the same or different culture) positively influences the success of the bank merger?

Not agree at all

Rather disagree 
Neither agree nor disagree

Somewhat agree

Totally agree

3.2 Do you consider that the cultural shock (conflicts in communication, differences in knowledge, conflicts within groups, uncertainty) positively influences the success of the bank merger?

Not agree at all

Rather disagree

Neither agree nor disagree

Somewhat agree

Totally agree

4. Economic dimension

4.1 Do you consider that the search for increased market share (winning positions in the market) positively influences the success of the bank merger?

Not agree at all

Rather disagree

Neither agree nor disagree

Somewhat agree

Totally agree

4.2 Do you consider that the search to increase profit (increase profit and minimize costs) positively influences the success of the bank merger?

Not agree at all

Rather disagree

Neither agree nor disagree

Somewhat agree

Totally agree

4.3 Do you consider that the search for value maximization (obtaining profitability) positively influences the success of the bank merger?

Not agree at all

Rather disagree

Neither agree nor disagree 
Somewhat agree

Totally agree

5. Strategic dimension

5.1 Do you consider that value creation (creating synergy) positively influences the success of the bank merger

Not agree at all

Rather disagree

Neither agree nor disagree

Somewhat agree

Totally agree

5.2 Do you consider that the search for innovation (new technological tools, new services) positively influences the success of the bank merger?

Not agree at all

Rather disagree

Neither agree nor disagree

Somewhat agree

Totally agree

5.3 Do you consider the search to increase the power of domination and influence (ability to dominate the various market players, influence and act on the market) positively influence the success of the bank merger?

Not agree at all

Rather disagree

Neither agree nor disagree

Somewhat agree

Totally agree

6. Political dimension

6.1 Do you think that the speed in the appointment of the management team positively influences the success of the bank merger?

Not agree at all

Rather disagree

Neither agree nor disagree 
Somewhat agree

Totally agree

6.2 Do you think that transparency and fairness in the appointment of managers positively influences the success of the bank merger?

Not agree at all

Rather disagree

Neither agree nor disagree

Somewhat agree

Totally agree

7. Bank merger performance

7.1 Do you consider that this operation is effective?

Not agree at all

Rather disagree

Neither agree nor disagree

Somewhat agree

Totally agree

7.2 Do you think that after this merger your bank's financial results will be positive?

Not agree at all

Rather disagree

Neither agree nor disagree

Somewhat agree

Totally agree

\section{Copyrights}

Copyright for this article is retained by the author(s), with first publication rights granted to the journal.

This is an open-access article distributed under the terms and conditions of the Creative Commons Attribution license (http://creativecommons.org/licenses/by/4.0/). 